ๆ שִ, Num. 21, 6. 8, eine Art Schlangen, die mit ihrem Hauche verbrennen. 750. 25-27.

חורים, Hoh. 1, 10, von ת תihe, Rang, weil die Farben und Edelsteine an dem sogenannten Schmucke in einer gewissen Reihenfolge und Rangordnung aufgereiht sind. 759, 28-30.

אטרתח, Gen. 44, 2, von תח, unten; das Wort bez. ein Gefäls, welches oft zum Reiten benützt wird, so dafs es unter dem Reiter sich befindet. 761, 18-30.

תליך, Gen. 27, 3, das Schwert, von חלה, hängen, weil es, wenn man es sich umgürtet, herunterhängt. 762, 22-24.

Budapest.

\title{
Seth und die Sethiten.
}

Von Friedr. Eduard König.

Als ich für die 2. Aufl. von H e rzog's Prot. Realenc. Bd. XIV, S. 162-167 den Art. „Seth und die Sethiten“ bearbeitete, habe ich im Laufe der Untersuchung ebenso, wie auf die Arbeiten anderer Vorgänger, auch auf Karl Bu d d e's Buch „Die Biblische Urgeschichte (Gen. 1-12,5) erläutert" Rücksicht genommen. Darauf hat $B$. im vorigen Jahrg. d. Zeitschr. (S. 298-302) behauptet, dafs ich in dem erwähnten Art. seine Aussagen oft mifsverstanden, oder nichtexistirende Lücken gerügt, oder wirklich von ihm gethane Aeufserungen an falscher Stelle verwendet habe. Den Vorwurf eines Mifsverständnisses oder irgendwelcher unrichtigen Verwerthung B.'scher Behauptungen mufs ich aber gänzlich zurückweisen. Zur Begründung gehe ich die $5 \mathrm{Nrn}$. der angeblichen B.'schen Berichtigung durch. 
1) In meinem von B. angegriffenen Satze ist, weil B. logisches Subject dieses Satzes ist, „genuiner Sinn" derjenige Sinn, welchen B. als den genuinen Sinn der elohistischen Sethitentafel erweisen will. Nun frage ich, ob B. durch seine Abhandlung (S. 89-116) eine andere Gesammtmeinung als diese begründen wollte, dals die elohistische Sethitenlinie bisher nur fälschlich als eine Reihe von Frommen aufgefalst worden sei, und ob unter den Argumenten dieser seiner Gesammtmeinung nicht auch das von mir angegebene vorkommt, dafs die thatsächliche Sündhaftigkeit des Menschengeschlechts auch die Sethiten ergriffen habe, da es ja unmittelbar hinter der Anführung dieses Argumentes bei ihm heifst: „Doch diese Ueberlegungen vermochten den Schein jener Sethitenheiligkeit nicht zu verdunkeln und haben es bis heute nicht vermocht." Es ist freilich ein fataler Lapsus, dafs dieses Argument nicht auf S. 103 des B.'schen Buches, wie ich angegeben hatte, sondern erst auf S. 104 steht.

2) Indem B. den grundlegenden Einwand, welchen ich gegen seine Zersplitterung der israelitischen Tradition zuerst (auf S. 163 meines Art.) angeführt habe, nicht ebenfalls zuerst, sondern; hinter den von S. 164-166 meines Art. hergenommenen Einwänden den Lesern vorführt, entsteht der Anschein, als habe ich seine „zwei verschiedenen

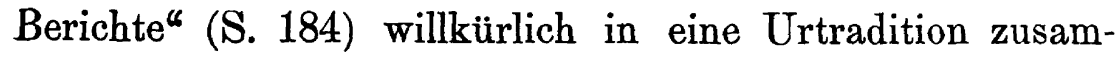
mengezogen. Hätte nur Bc an erster Stelle den Vorwurf mir gemacht, welchen er in seinem Aufsatze an letzter Stelle gebracht hat, so hätten die Leser gewufst, dafs ich ausdrücklich und mit Angabe von Gründen alle diejenigen seiner Behauptungen abgelehnt habe, deren Ignorirung er mir als Entstellung seiner Darlegung vorwirft. Denn die Leser hätten dann gewufst, dafs ich in meinem Art. „zwei verschiedene Berichte ${ }^{*}$ über die erste Entwickelung des Menschengeschlechts den Israeliten nicht zuschreiben, dafs ich nicht die eine Stammtafel nur als Ueberarbeitung der 
andern betrachten, und dafs ich den Seth nicht als Ersatz des Kain, sondern nur als den des Abel betrachten konnte. Vgl. unten Nr. 5!

3) B. stellt selbst nicht in Abrede, dafs er in seinem Buche nicht die Frage aufgeworfen hat, weshalb gerade bei Adam die Ueberlieferung zwei Söhne genannt habe. Nachdem ich diese Frage gestellt habe, giebt B. die Antwort, dafs er z. B. Sem neben Ham kenne. Er hat also übersehen, dafs es sich um die Frage handelt, weshalb unter den Urvätern gerade dem Adam zwei Söhne, Kain und Abel (Seth), von der hebr. Ueberlieferung (und zwar schon in der jahvistischen Sethitentafel Gen. 4, 25 f.) zugeschrieben worden sind. Wenn dies schon an sich nicht zufällig sein kann, so lehrt auch noch überdies ein Blick auf die Söhne des Lamech (in der jahvistischen Kainitentafel Gen. 4, 17-24), dafs blofs bei denjenigen Urvätern mehrere Söhne mit Namen genannt sind, von welchen nach der Idee der Israeliten verschiedene Culturrichtungen ausgegangen waren.

4) B. bemäkelt meinen Satz, dals Henoch eine Generation vertreten soll. Es ist aber doch offenbar, dafs die Urväter (Gen. 5) als Generationsvertreter gemeint sind weil allemal der Erstgeborene anstatt aller seiner Geschwister genannt ist. Es durfte auch bis daher als für jedermann deutlich angesehen werden, dals damit gemeint sei, Seth sei statt aller (relativ frommen) Kinder Adams, Enos statt aller (relativ frommen) Enkel Adams genannt u. s. w. Ich kann deshalb nicht annehmen, dafs jemand unter den Lesern der Prot. Realenc. mit B. diese meine Sätze neu findet und in dieselben den Sinn legen zu dürfen meint, dafs alle Glieder der von Henoch vertretenen Generation 365 Jahre alt geworden, und dals sie alle am 365. Geburtstage von Gott hinweggenommen worden seien.

5) Ich habe an demjenigen Punkte meines Artikels, wo die Untersuchung mich zuerst zur genaueren Berück- 
sichtigung des B.'schen Buches führte, erklärt, dals ich die Meinung für unrichtig halte, ein Theil (eine Schule; nirgendwelcher Winkel hebräischer 'Ueberlieferung", Budde a. a. O. S. 196) des Volkes Israel habe Traditionen, welche die ganze Nation angingen, selbständig gebildet. Ich habe den grundlegenden Dissensus, welcher betreffs des Grades der Einheitlichkeit der israel. Ueberlieferung zwischen B. und mir besteht, berühren müssen, weil ich sonst keine Basis besessen hätte, von welcher aus ich im weiteren Fortgang meines Art. die Anschauungen B.'s hätte ablehnen können. Es mufste dabei vollständig gleichgiltig sein, ob die aus B.'s Buch citirten Worte die Sethitentafel direct betreffen oder nicht; da dieselben die literarhistorische Grundanschauung aussprechen, welche von allen Untersuchungen des B.'schen Buches vorausgegesetzt wird. Dals ich ferner bei der Citirung der B.'schen Worte dieselben im localen Sinne auffassen, also $n$ den Winkel $^{\text {" }}$ als irgend eine Abtheilung Israels und nicht als eine Partie der Tradition selbst verstehen mufste oder wenigstens durfte, dazu berechtigte mich der Umstand, dafs B. auch S. 79 ein Moment der Urtradition minnerhalb des Volkes Israel einer Schule angehören" lälst, dals er auch S. 235 von „verschiedenen Stufen derselben Schule redet und S. 463 von „denjenigen Kreisen spricht, aus denen die 2. Gestalt des Jahvisten" hervorgegangen sein soll.

Demnach glaube ich, dafs B. ohne jeden Anlals und obgleich ich im ruhigen Tone einer wissenschaftlichen Erörterung mich mit ihm auseinandergesetzt hatte, mich zum Zielpunkt eines Angriffes gemacht hat. 